\title{
Editorial
}

\section{Bridging Frameworks for Understanding Numerical Cognition}

\author{
Anderson Norton*a, Julie Nurnberger-Haag ${ }^{\mathrm{b}}$
}

[a] Department of Mathematics, Virginia Tech, Blacksburg, VA, USA. [b] School of Teaching, Learning, and Curriculum Studies, Kent State University, Kent, $\mathrm{OH}$, USA.

Journal of Numerical Cognition, 2018, Vol. 4(1), 1-8, doi:10.5964/jnc.v4i1.160

Published (VoR): 2018-06-07.

*Corresponding author at: 434 McBryde Hall, Virginia Tech, Blacksburg, VA, 24061-0123, USA. E-mail: norton3@vt.edu

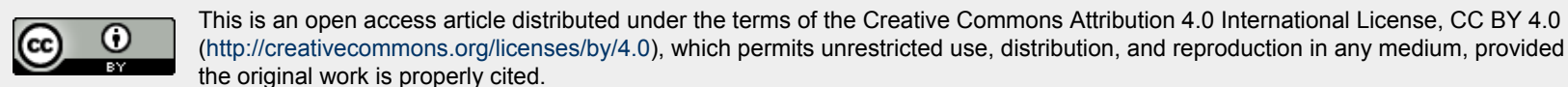

This special issue represents an attempt to build bridges between research in mathematics education and psychology. Although the disciplines differ in the way they frame specific research questions, these two fields concern themselves with many of the same problems, especially problems related to mathematical learning. Too often, however, their respective communities talk past one another, not knowing how to integrate work from the other field. In a commentary published in this journal, Dan Berch (2016) voiced skepticism about whether it was even possible to do so. He cited divergent methodologies, theoretical frameworks, and epistemologies as insurmountable obstacles. Here, we present articles that provide reason for optimism while elucidating key challenges for each field.

The articles presented in this issue contribute to our understanding of mathematical development in the domain of numerical cognition while integrating perspectives to various degrees. Some of the articles represent literature primarily from the authors' own discipline to call for future research and application in the other field. Other articles examine interdisciplinary research relationships themselves. In "Bridging psychology and mathematics education," Martha Alibali and Eric Knuth report on a particularly productive collaboration, which has generated several research publications and numerous insights into ways that students conceptualize mathematical equations. Additional articles—one led by educational psychologist Helena Osana and another led by mathematics educator Xenia Vamvakoussi-directly address Berch's concerns and the obstacles he identified in relation to interdisciplinary collaborations.

In this editorial we elaborate on two epistemological obstacles to bridge building: differing perspectives on the nature of mathematics, and differing perspectives on research (which lead to different methodological choices). We draw upon findings from papers presented in this special issue to identify potentially productive ways to navigate these obstacles. We close with suggestions for future collaborations. 


\section{Theoretical Frameworks and Epistemology: Problematizing Mathematics}

As noted by Berch (2016) and others (e.g., Bruer, 1997), divergent frameworks and epistemologies exacerbate the challenges of interdisciplinary research. After all, theoretical frameworks frame even the way we pose questions. Here we address the challenge inherent in divergent views of mathematics itself.

Davis and Hersh (1981) stated that Platonism prevails as the default epistemology of mathematics. The apparent certainty of mathematics renders it true in the minds of most people, separate from culture and cognition, so that it seems universal, as in the language of God or the fabric of the universe. $2+2=4$. How can we imagine otherwise, and how can we not imagine the existence of a perfect cube, somewhere, although no such thing exists in the physical world we experience? In tackling such questions, Plato posited a heavenly world in which numbers and shapes exist and have existed, for all time. Today, many mathematicians embrace Platonism as motivation for the immutable truths their proofs presume to unveil.

Like mathematicians, mathematics educators recognize mathematics as a unique form of knowledge. However, motivation for mathematics education research comes from a desire to understand mathematics as a product of the human mind and the environments in which it develops (especially classrooms), rather than pre-existing in a Platonic world. Problematizing mathematics - what it is and how people develop it-is very much at the heart of mathematics education. Mathematics education includes several philosophies describing mathematics as a human invention (Ernest, 2004). In contrast, psychology-based research tends to study how people develop mathematical knowledge without questioning the nature of mathematics itself.

Within mathematics education research, mathematics is often defined by a community with particular values and norms (socio-cultural perspective; e.g., D'Ambrosio, 1986), by particular kinds of constructions that ultimately depend upon the learner's mental activity (cognitive perspective; e.g., Tall, 2002), or some combination of the two (emergent perspective; e.g., Cobb \& Yackel, 1996). The articles appearing in this special issue tend to focus on the cognitive perspective, though the article by Gutierrez, Brown, and Alibali, which investigates social interactions of pairs of students while they constructed knowledge, provides an example of an interdisciplinary team that blended these perspectives.

Among mathematics education researchers who adopt a cognitive perspective, Piaget's work in psychology has had considerable influence, especially among constructivists. In Piaget's constructivist epistemology (von Glasersfeld, 1995), mathematical knowledge is distinguished from other forms of knowledge while demonstrating its basis in students' coordination of mental actions (Beth \& Piaget, 1966). Radical constructivists also draw upon neo-Piagetian psychologists, such as Pascual-Leone and Fischer, but relatively little research in psychology maintains the mathematical distinction Piaget made. In particular, radical constructivism opens the door to students' mathematics, apart from formal mathematics, as presented in textbooks (Steffe, 1991). It also provides a basis for building second-order models of students' mathematics, as exemplified in the article, "Time as measure," by Earnest Gonzales, Eastman, and Plant. Such model building stands in contrast to research that documents students' mathematics as a subset of formal mathematics by noting which aspects of formal mathematics students do or do not understand. This is an essential feature of cognitive research in mathematics education, and it depends on problematizing mathematics. 
Embodied cognition espouses an epistemology of mathematics based in sensori-motor actions (Núñez, 2012). From an embodied perspective, "cognitive processes are deeply rooted in the body's interactions with the world" (Wilson, 2002, p. 625). This perspective leads researchers of embodied cognition to study students' sensori-motor activity, including imagined activity that might be inferred from students' use of language and gestures (Glenberg, 2010). Research on mathematics education from an embodied perspective draws heavily on empirical research and theory from both mathematics education and psychology. The article, "You can count on your fingers," by Firat Soylu provides an example.

From both constructivist and embodied perspectives, mathematics is a product of "perceptuo-motor-imagined activity" (Beth \& Piaget, 1966; Nemirovsky \& Ferrara, 2009, p. 162), wherein mathematics education and psychology are inherently integrated. However, these perspectives require researchers to problematize mathematics. In contrast, psychologists often employ frameworks that directly relate innate numerical sense (e.g., subitizing) with school-taught algorithms. For example, Dehaene and Cohen's (1997) triple-code model attempts to link the Approximate Number System to exact computation methods for addition and multiplication. The missing link from a constructivist perspective is students' mathematics, which is based in students' own actions. Progress can be seen in the "Subtraction by addition" article by Torbeyns, which compares the schooltaught algorithm for subtraction to a student-invented algorithm.

By focusing on students' mathematics, mathematics educators and psychologists might be better poised to benefit from one another's research. Mathematics educators can gain a better appreciation for the utility of psychological constructs in building models of students' mathematics, and psychologists can free themselves from the mathematics of textbooks by focusing on the mathematics that students construct. Three articles struggle with the issue of reconciling students' mathematics and formal mathematics. The article by Matthews and Ellis provides windows into their respective disciplinary perspectives related to students' understanding of fractions. Osana and Proulx do so for interdisciplinary research on mental arithmetic of whole number operations. Coles and Sinclair examine curricular influences on students' mathematics and question whether there is such a thing a normal development in students' mathematics, particularly in the context of developing number knowledge.

\section{Methods for Solving Problems of Mathematical Learning}

Research methods are more than tools; they are accepted practices in particular disciplines based on particular epistemological stances (Creswell, 2009). Differences in methodological approaches can be viewed as simply serving different purposes (Creswell, 2009). Sometimes cognitive psychologists will use qualitative methods to analyze natural behavior, and sometimes mathematics education researchers will conduct a controlled experiment; both rarely occur. Although mathematics education emerged from psychological roots, the fields often have divergent approaches (Lester \& Lambdin, 2003). Psychologists use controlled experiments to isolate variables, so observing naturalistic behavior such as classrooms of multiple teachers with students teaching the same topic leaves many factors unexplained. Mathematics education researchers often observe classrooms because the problems they intend to solve have to be applicable in these complex systems of human interaction; thus many mathematics education researchers believe isolating variables will inhibit successfully scaling up controlled study research to how humans in classrooms work. Both are correct, so to make true progress on problems of learning mathematics, literature and methods from each field should be used to 
influence the methodological choices of the other, even if in the end one maintains one's primary epistemological stance. Osana and Proulx described some ways in which they influenced each other, yet essentially conducted two studies, accepting rather than agreeing on many methodological choices. They detail how they each responded to the pragmatic constraints of a real classroom to plan instruction, data sources, and analysis that met each of their separate research objectives emerging from their epistemological stances.

With this special issue we hope to share perspectives that could enable researchers from each field to accept research questions investigated in another field as worthy of investigation and consideration. The epistemological stances and common methods guide the types of questions researchers typically ask. In psychology journals, research foci are typically framed as yes or no questions of hypotheses to test, whereas in mathematics education journals the research focus may be framed as a statement of purpose. Although it may seem subtle, this difference can create barriers for readers who either claim a study in the opposite domain oversimplified the issues into dichotomous questions, or disregard a study as not having any research questions. Knowledge of the epistemological stances and goals of research in respective fields could help researchers understand these purposes and questions and the resulting methodological choices people make to accomplish research goals. This collection of articles reflects different methodological approaches across fields to show mutual respect and how collaborations provide opportunities to clarify and strengthen research questions and methodological choices.

Consistent with methodological approaches typically employed in psychology-what Creswell (2009) identifies as a post-positivist perspective-two articles employed surveys as data sources to inform our understanding of mathematical cognition: Walkington, Cooper, and Akinsiku analyzed survey data about typicality; and Espinosa investigated how conceptions of utility of mathematics relate to self-confidence. Coles and Sinclair (consistent with theoretical stances rooted in mathematics, mathematics education, and philosophy) chose the method of providing existence cases to counter assumptions that researchers in both mathematics education and psychology make when they interpret data about instruction. The implications of each of these articles could provide fruitful insights to inspire other researchers to approaches problems in new ways. Regardless, the implications of each article are worthy of consideration by mathematics educators and psychologists alike.

Alibali and Knuth, as well as Osana and Proulx, explicitly discuss their respective methodological approaches and conflicts within their respective cross-disciplinary collaborations. Both offer summaries and insights about how researchers from respective disciplines consider reliability and validity in their methodological choices. Through the process of reviewing manuscripts that appear here and others that were reviewed, we encourage realistic expectations when choosing to adopt a new methodology or theoretical perspective, because there will be a learning curve. Experimental researchers with strong research may find a new appreciation for the difficulties of qualitative approaches they attempt to adapt. Similarly, qualitative researchers who try to quantify their results may find they need to test assumptions, statistically control variables, and cautiously interpret their results in light of the seemingly objective statistical output (Hill \& Shih, 2009).

\section{Future Directions}

What does it mean to build disciplinary bridges? This special issue offers windows into a variety of ways to forge and define cross-disciplinary bridges to strengthen our ability as researchers to more fully solve problems 
of mathematical learning. The articles in the special issue serve as examples of ways we might apply research from one field to the other. Additionally, some of the articles reflect long-standing cross-disciplinary partnerships.

\section{Bridging by Reading}

As Alcock et al. noted, "cross-citations are comparatively rare" (2016, p. 22). Similarly, a key criticism from reviewers for this special issue was that authors from a single field seeking to bridge to another field claimed no or little literature existed in the other field about the topic under investigation. We view this critique as a fundamental obstacle to building bridges and identify a few contributing factors: a) knowing where and how to search for literature in the other field; b) bridging disciplinary jargon or terms used to find the constructs of interest; and c) appropriately interpreting the literature from another field. Consequently, we offer suggestions gleaned through the process of creating this special issue in order to help researchers overcome each of these obstacles.

\section{Finding Literature}

In another article that sought to encourage communication between psychological research fields and educational research in mathematics, Alcock et al. (2016) identified some of the journals and conferences with which each field engages (Alcock et al., 2016). Mathematics education researchers seeking to bridge to psychology might find the databases PsychInfo and Psych Abstracts helpful because they include child development as well as psychology. Suggestions for cognitive psychology researchers bridging to mathematics education include reading general education journals such as those of the American Education Research Association. Although an educational database called ERIC exists, this has never had the functionality of Psychlnfo or Psych Abstracts, so mathematics education researchers need to use multiple means of searching for literature within their own field, which creates even greater barriers for others seeking to find relevant research in mathematics education. The following web site provides a fairly comprehensive list of journals in which mathematics education researchers as well as teachers publish: https://mathedjournals.wikispaces.com. Samuel Otten, a mathematics education researcher with an undergraduate minor in psychology, a Master's degree in mathematics, and a $\mathrm{PhD}$ in mathematics education, also began and maintains a platform for those researchers interested in disseminating research on learning of mathematics: http://mathed.podomatic.com. This website could serve multiple bridge-building functions such as providing insights about topics being studied, how researchers use terms, and a way for each to disseminate our work individually or collectively.

\section{Learning to Speak Each Other's Languages}

Terms used in each field may have dissimilar meanings, and each field may be unaware of search terms to describe the same or similar underlying construct. Even though Google Scholar and other means are available to all researchers, the search results may not be as productive without having built relationships with critical colleagues in other fields to learn each other's terms. For example, in this journal (begun by an editorial board from psychology and child development) "number" is used as a proxy for mathematics, writ large. In mathematics education research, "number" carries a more limited meaning referring to the domain of number and operations and generally excluding other domains, such as algebra, statistics and probability, and geometry. To search within a cognitive psychology journal it may help to use "math" to narrow the search, whereas in mathematics education journals researchers might specify a very particular topic such as "integers." 
Training, learning, knowledge, intervention, and instruction are other terms that can cause miscommunications between disciplines. For example, when psychologists write about training or intervention, these terms evoke remnants of behaviorist perspectives for mathematics educators, which may deter them from reading further, so changing one's language when writing for a specific audience may be warranted to aide communication. In fact, one common critique from mathematics educators reviewing psychology-based submissions was that the terms used for mathematics topics did not reflect the mathematical construct.

If one seeks to build bridges without an interdisciplinary collaborator, seeking a critical colleague as a conversation partner or informal reviewer would be valuable to ensure that we appropriately use theories and interpret results from the other field correctly. We suggest this in response to reviewer comments on multiple manuscripts.

\section{Bridging by Being There}

Alibali and Knuth suggest that researchers of numerical cognition attend conferences and serve as reviewers in the other discipline. During the development of this special issue, the journal established a partnership with the Mathematical Cognition and Learning Society (http://the-mcls.org), which primarily psychology-focused researchers have attended. The primary conference for mathematics educators in North America who research numerical cognition is the North American Chapter of the International Group for the Psychology of Mathematics Education (www.pmena.org). Research on numerical cognition will benefit from advertising calls for proposals across such disciplinary conference boundaries. We recruited many members of PME-NA into the Journal of Numerical Cognition reviewer system so that they might offer their perspectives on potential contributions to the special issue as well as future submissions. Thus, the Journal of Numerical Cognition and this special issue, in particular, offer tangible examples of ongoing efforts to bridge the divide.

\section{Strengthening Bridges}

When researchers speak of theory, they naturally take for granted that they will be understood at the level they intend to be understood. Yet, because these various levels of meaning are simultaneously at play, what researchers take for granted may not be shared by others. They sometimes find themselves talking about a theory at one level, while their colleagues are thinking about it at quite another level. At best, this leads to muddled communication. At worst, researchers are left wondering how intelligent people could be so obtuse as to misunderstand what they mean. (Flinders \& Mills, 1993, p. xiv as cited in Ravitch \& Riggan, 2017, p. 27).

The issue described in the quote occurs even within disciplines, but is further compounded when we seek to understand and apply theories across disciplinary boundaries. When graduate students in education learn how to conduct research, they typically learn about qualitative and qualitative research paradigms and the epistemological perspectives that lead to such methodological choices. Most often, their research experiences on projects and the articles they read reinforce the qualitative paradigm. In contrast, graduate students in psychology may not have a course that introduces them to qualitative research and related epistemologies. Instead they read quantitative studies with experimental designs and work on research projects that implement these methods. Alibali and Knuth's paper describes the issue this might raise for communication. 
Whereas research in psychology often explicitly refers to mechanisms, mathematics education research rarely does and often uses theoretical frameworks in implicit ways. Related obstacles that arose during the production of this special issue lead us to suggest that questions for further discussion could comprise an entire special issue in itself. What do mathematics education researchers consider a theory? What do cognitive psychologists consider a theory, and how does it relate to a mechanism?

\section{Funding}

The authors have no funding to report.

\section{Competing Interests}

The authors have declared that no competing interests exist.

\section{Acknowledgments}

In producing this special issue, we appreciate the support of John Towse, editor of the Journal for Numerical Cognition (JNC), and the North American Chapter of the International Group for the Psychology of Mathematics Education (PME-NA). We also thank a host of JNC reviewers, many of whom signed up as journal reviewers specifically for this special issue. These reviews and the authors of the articles included here represent a substantial commitment to building bridges.

\section{References}

Alcock, L., Ansari, D., Batchelor, S., Bisson, M.-J., De Smedt, B., Gilmore, C., . . Weber, K. (2016). Challenges in mathematical cognition: A collaboratively-derived research agenda. Journal of Numerical Cognition, 2, 20-41. doi:10.5964/jnc.v2i1.10

Berch, D. B. (2016). Disciplinary differences between cognitive psychology and mathematics education: A developmental disconnection syndrome. Journal of Numerical Cognition, 2(1), 42-47. doi:10.5964/jnc.v2i1.23

Beth, E. W., \& Piaget, J. (1966). Mathematical epistemology and psychology (W. Mays, Trans.). New York, NY, USA: D. Reidel.

Bruer, J. T. (1997). Education and the brain: A bridge too far. Educational Researcher, 26(8), 4-16. doi:10.3102/0013189X026008004

Cobb, P., \& Yackel, E. (1996). Constructivist, emergent, and sociocultural perspectives in the context of developmental research. Educational Psychologist, 31(3-4), 175-190. doi:10.1080/00461520.1996.9653265

Creswell, J. W. (2009). Research design: Qualitative, quantitative, and mixed methods approaches. Los Angeles, CA, USA: SAGE.

D'Ambrosio, U. (1986). Socio-cultural bases for mathematical education. In M. Carss (Ed.), Proceedings of the Fifth International Congress on Mathematical Education (pp. 1-6). Boston, MA, USA: Birkhäuser Boston.

Davis, P. J., \& Hersh, R. (1981). The mathematical experience. New York, NY, USA: Viking Penguin. 
Dehaene, S., \& Cohen, L. (1997). Cerebral pathways for calculation: Double dissociation between rote verbal and quantitative knowledge of arithmetic. Cortex, 33(2), 219-250. doi:10.1016/S0010-9452(08)70002-9

Ernest, P. (2004, July). What is the philosophy of mathematics education? Paper presented at the International Congress on Mathematics Education (ICME 10), Copenhagen, Denmark.

Glenberg, A. M. (2010). Embodiment as a unifying perspective for psychology. Wiley Interdisciplinary Reviews: Cognitive Science, 1, 586-596. doi:10.1002/wcs.55

Hill, H. C., \& Shih, J. C. (2009). Examining the quality of statistical mathematics education research. Journal for Research in Mathematics Education, 40, 241-250.

Lester, F. K., \& Lambdin, D. V. (2003). From amateur to professional: The emergence and maturation of the US mathematics education research community. In G. Stanic (Ed.), A history of school mathematics (Vol. 2, pp. 1629-1700). Reston, VA, USA: National Council of Teachers of Mathematics.

Nemirovsky, R., \& Ferrara, F. (2009). Mathematical imagination and embodied cognition. Educational Studies in Mathematics, 70, 159-174. doi:10.1007/s10649-008-9150-4

Núñez, R. E. (2012). On the science of embodied cognition in the 2010s: Research questions, appropriate reductionism, and testable explanations. Journal of the Learning Sciences, 21, 324-336. doi:10.1080/10508406.2011.614325

Ravitch, S. M., \& Riggan, M. (2017). Reason and rigor: How conceptual frameworks guide research (2nd ed.). Thousand Oaks, CA, USA: SAGE.

Steffe, L. P. (1991). The constructivist teaching experiment: Illustrations and implications. In E. von Glasersfeld (Ed.), Radical constructivism in mathematics education (pp. 177-194). Dordrecht, The Netherlands: Springer.

Tall, D. (2002). The psychology of advanced mathematical thinking. In D. Tall (Ed.), Advanced mathematical thinking (pp. 3-21). Dordrecht, The Netherlands: Springer.

von Glasersfeld, E. (1995). A constructivist approach to teaching. In L. P. Steffe \& J. Gale (Eds.), Constructivism in education (pp. 3-15). Hillsdale, NJ, USA: Erlbaum.

Wilson, M. (2002). Six views of embodied cognition. Psychonomic Bulletin \& Review, 9(4), 625-636.

doi:10.3758/BF03196322 